\title{
Cloud Video Conferencing for Geographically Distributed Colleges
}

\author{
Hamad Odhabi (Corresponding Author)
}

Higher Colleges of Technology, United Arab Emirates. E-mail: hodhabi@hct.ac.ae

\author{
Mohamad Tabbara
}

Higher Colleges of Technology, United Arab Emirates. E-mail: mtabbara@hct.ac.ae

\section{Peter Heath}

Higher Colleges of Technology, United Arab Emirates. E-mail: pheath@hct.ac.ae

Received: December 4, 2013 Accepted: December 23, 2013 Published: December 24, 2013

doi:10.5296/jet.v1i1.4664 URL: http://dx.doi.org/10.5296/jet.v1i1.4664

\begin{abstract}
This paper will discuss the use of cloud-based video conferencing services across a geographically dispersed college system - to improve communication amongst academic staff and to provide access to educational programmes for small, scattered cohorts of students. The paper will discuss student acceptance of the technology and will present guidelines for making course delivery more effective and interactive, as well as explore new techniques that transform traditional closed classes into open global hubs that can integrate customized seminars and incorporate specialist guest speakers. It will also investigate the utilisation of this technology at the Higher Colleges of Technology, UAE, and compare it to traditional video conferencing rooms in terms of cost, access and utilisation. Concluding remarks will be presented and discussed at the end of the paper.
\end{abstract}

\section{Introduction}

The Higher Colleges of Technology (HCT) in the United Arab Emirates comprise campuses in 17 locations across the country. HCT campuses deliver programmes in Computer \& Information Science, Applied Communications, Engineering, Business, Health Science and Education. Prior to August 2013, the College Director (President) was in charge of both academic and administrative functions, while Central Services was responsible for academic programme design and development - course outlines, learning outcomes, assessments, 
international accreditation, etc. Each campus was responsible for programme delivery, quality assurance/improvement and linkage with local \& international industry. Academic staff reported to the College Director. However this structure provided limited opportunities for collaboration by faculty members teaching the same course across different campuses. This resulted in significant duplication of effort in terms of course material development, assessment strategies and resources.

This academic year HCT has transitioned to a new structure. Now, faculty members and campus chairs belong to a system-wide faculty under the leadership of an Executive Dean. For example, faculty members of the Computer Information Science (CIS) division report to the Executive Dean of Computer Information Science \& Applied Communications (CISAC), through their campus departmental chair. In this new structure, the College Director's role is focused on administration of the campus and community outreach.

The new structure is expected to facilitate improved collaboration amongst faculty members in terms of sharing best practices, course content development, assessment moderation, applied research, and so on. Communication amongst academic staff is critical to the success of the new structure. Travel distances make it challenging for all parties to stay connected and resolve urgent/emerging issues quickly and effectively. To overcome this problem, the CISAC Faculty introduced Zoom cloud video conferencing technology for teaching, student support and management. Zoom provides a service similar to Skype, but allows 25 users to attend the same meeting simultaneously and provides high-definition (HD) video and high-quality audio, complete with screen sharing and recording capability.

The aim of this paper is to assess the use of Zoom in improving communication and collaboration amongst teaching and management staff located at a distance from each other and to provide access to educational programmes for small, geographically scattered cohorts of students.

The next section will discuss educational uses of cloud video conferencing in general, and present examples of Zoom usage in the CISAC Faculty. Section 3 will present the results of a survey given to students currently studying a course via Zoom. Section 4 will present guidelines aimed at making course delivery more effective and interactive. Section 5 will discuss the utilisation of this technology within the Higher Colleges of Technology and compare it to traditional video conferencing technology in terms of cost, access and utilisation. Section 6 will present directions for future research. Concluding remarks will be presented at the end of the paper

\section{Cloud Video Conferencing in Education:}

Aydin (2012) concluded in his research that video conferencing can allow diverse perspectives into the classroom in all academic disciplines and has the added benefit of enabling students from different countries to talk to each other. Such interaction will encourage students to experience new cultures from a different perspective (Brown, 2011). The advancement in videoconferencing technology has made it powerful to bring diverse perspectives into the classroom in all academic disciplines (Journell, 2011). 
Video conferencing presents a unique opportunity for teaching students based in rural settings (Parrish \& Mila, 2008). Zoom is currently being used for two types of scenarios: (i) students are in a different location than the instructor; (ii) students are in multiple locations. This allows students in different campuses to work together on the same project.

Merryfield (2000) noted that faculty members who value globalisation and have travelled or lived in diverse geographical or cultural locations have a wealth of personal experience, and that video conferencing can bring that experience to the classroom. This technology has also brought highly regarded international guest speakers directly to the classroom, and the CISAC faculty has had much success in inviting guest speakers to Zoom classes from the IT industry, academia and public industry in the UAE. Moreover, students using Zoom have the opportunity to transcend barriers of distance and time to participate in both educational and industrial seminars across the UAE, as well as collaborate in their class projects and assignments according to the latest industrial needs and standards. The logistics required for this level of collaboration have been greatly reduced, since guest speakers only need a computer, tablet or smart phone to connect with the class and deliver their presentations.

Traditional video conferencing rooms were frequently limited from a logistics perspective (Lim, 2009; Breny 1999). For example, the traditional video conference was limited to people close to the equipped rooms, or restricted by the number of people the room could accommodate and the number of links available. With cloud video conferencing, participants can easily connect wherever there is an internet connection. Another advantage of connecting from a laptop or tablet is that the participant has direct access to all the data and documents needed during the meeting or class.

\section{Examples of Cloud Video Conferencing within CISAC:}

The list below shows examples of Zoom usage within the CISAC Faculty:

Management meeting: 20 members of the CISAC management team from 17 locations meet weekly to discuss all aspects relating to the delivery of CISAC programs. Minutes of the meeting are recorded and include follow-up actions. One of the meeting's agenda items is focused on positive updates and best practice shared amongst team members.

Course team meeting: Faculty members who teach the same course/module meet at least three times during the semester to discuss course progress, student issues, course outlines and assessment strategies, and to share course content.

Teaching: This semester, three courses are being delivered via Zoom technology. Further courses will be delivered via Zoom in the next semester in accordance with the CISAC strategic plan. In addition, CISAC will offer short courses for secondary school students who would like to familiarize themselves with higher education while they are still in school. The faculty and the relevant school principal will nominate the students.

Dissertation Defence: Students in the HCT Master of Information Systems Management program are required to write and defend a research dissertation. Zoom allows qualified examiners to attend the viva without physically traveling between cities. 
Faculty office hours: Each faculty member offers a specified number of office hours during which they can be contacted by students either face-to-face or via Zoom for a discussion on course-related issues.

Student focus groups: For those courses delivered through Zoom, the faculty member divides the class into small groups (3 to 4 members each; weaker students distributed among stronger students). These groups meet once a week outside regular class hours to discuss course related issues, projects, seminars and even to prepare for quizzes and exams.

Research collaborations: The CISAC research group hosts periodic seminars through Zoom.

Professional development: Multiple professional development sessions have been delivered via Zoom to CISAC members at multiple locations.

Industry guest speakers: Industry speakers have been involved in two courses, as well as in one-to-one and group management meetings.

Project alignment: Students, each in their respective fields of studies, are given the opportunity to communicate with leaders and pioneers from academia and industry to discuss project opportunities that are related directly to UAE industrial needs and align with international standards. This semester two groups from Zoom classes are working on IEEE Robotic \& Automation Society UAE chapter customized projects.

\section{Student Acceptance}

Currently two Bachelor-level courses being delivered via Zoom. In both courses, the students are in Fujairah while the instructor is in Abu Dhabi (259 km apart). There are a total of 34 students in the two courses. Teaching with Zoom started in September 2013, and the courses are typically scheduled for 4 hour-long sessions per week for 16 weeks. The two courses are being delivered in alignment with HCT's standard policies and procedures. In particular, the course outlines, e-texts, materials, assessments, etc are the same as for sections of these courses delivered elsewhere.

It is interesting to note that after using Zoom for more than three months, the class average for assignments, projects and tests is $85.2 \%$. This is 7 points higher than face-to-face classes offered for the same courses to different students in the previous semester.

The students in these classes were surveyed to determine their satisfaction with cloud-based learning using Zoom. The survey questions focused on the students' attitude to Zoom in both pedagogical and technological areas. The survey was delivered through Freeonlinesurveys.com and consisted of three parts. The first part comprised 6 questions about the general usability of technology/Zoom by the students. The second part consisted of 13 questions on Zoom as a learning tool. The third part consisted of 11 questions measuring students' overall satisfaction with Zoom. Students responded to the survey anonymously. Of the 34 students in the classes, 32 responded to the survey. The results of the survey were tabulated and analyzed using online tools available through the Freeonlinesurveys.com website. 


\section{Ml Macrothink}

Overall, $51.5 \%$ of the respondents expressed that they were extremely satisfied with Zoom, $27.3 \%$ were quite satisfied and $21.2 \%$ were moderately satisfied. Students were asked about several of Zoom's features. The recording capability rated highest, with $94 \%$ of students extremely or quite satisfied. This feature allows students to review lessons after class. Students also rated the video quality highly, with $90 \%$ stating they were extremely or quite satisfied. Latency in the video-sharing feature was found to be close to non-existent, while the synchronization between audio and video was reported to be very good. Also, students rated the ability to collaborate via Zoom and share their screens to solve problems as one of Zoom's most effective features.

Of the features studied, audio quality scored lowest, with $18 \%$ extremely satisfied, $48 \%$ quite satisfied, $24 \%$ moderately satisfied and $9 \%$ only slightly satisfied. It has been discovered by the faculty member that the audio quality sometimes degrades if the student or teacher connects via the wireless network in the campus. For this reason, the faculty member currently runs all sessions using a wired connection with a dedicated MAC address. In addition, the faculty has a good-quality external microphone with a noise reduction feature and students are encouraged to use good-quality microphones as well. Almost all students agreed that Zoom is an extremely useful technology and very easy to use. $75 \%$ of respondents stated that they would definitely continue using Zoom for future courses and $90 \%$ would recommend it to their friends and colleagues at the HCT.

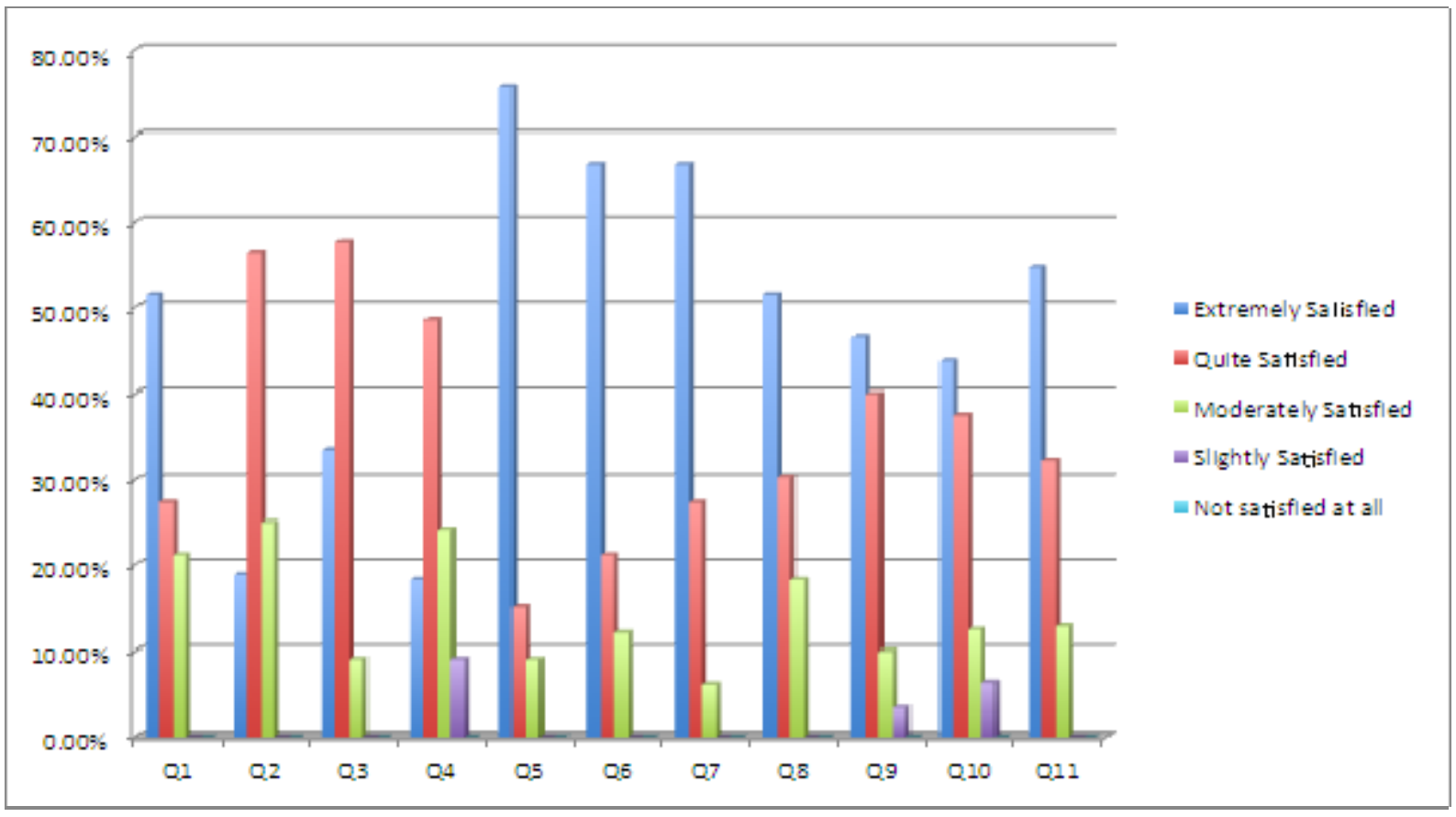

Figure 1. The results of student satisfaction survey 
Table 1. Student satisfaction survey of studying a course using Zoom videoconferencing technology

\begin{tabular}{|c|c|c|c|c|c|c|}
\hline Question & & $\begin{array}{l}\text { Extremely } \\
\text { satisfied }\end{array}$ & $\begin{array}{l}\text { Quite } \\
\text { satisfied }\end{array}$ & $\begin{array}{l}\text { Moderately } \\
\text { satisfied }\end{array}$ & $\begin{array}{l}\text { Slightly } \\
\text { satisfied }\end{array}$ & $\begin{array}{l}\text { Not } \\
\text { satisfied } \\
\text { at all }\end{array}$ \\
\hline Q1 & $\begin{array}{l}\text { Please indicate your } \\
\text { overall level of } \\
\text { satisfaction using } \\
\text { Zoom: }\end{array}$ & $51.5 \%$ & $27.3 \%$ & $21.2 \%$ & $0.0 \%$ & $0.0 \%$ \\
\hline Q2 & $\begin{array}{l}\text { Overall connection } \\
\text { speed }\end{array}$ & $18.8 \%$ & $56.3 \%$ & $25.0 \%$ & $0.0 \%$ & $0.0 \%$ \\
\hline Q3 & Video quality & $33.3 \%$ & $57.6 \%$ & $9.1 \%$ & $0.0 \%$ & $0.0 \%$ \\
\hline Q4 & Audio quality & $18.2 \%$ & $48.5 \%$ & $24.2 \%$ & $9.1 \%$ & $0.0 \%$ \\
\hline Q5 & Sharing screen & $75.8 \%$ & $15.2 \%$ & $9.1 \%$ & $0.0 \%$ & $0.0 \%$ \\
\hline Q6 & Chatting console & $66.7 \%$ & $21.2 \%$ & $12.1 \%$ & $0.0 \%$ & $0.0 \%$ \\
\hline Q7 & Recording the lesson & $66.7 \%$ & $27.3 \%$ & $6.1 \%$ & $0.0 \%$ & $0.0 \%$ \\
\hline Q8 & General user interface & $51.5 \%$ & $30.3 \%$ & $18.2 \%$ & $0.0 \%$ & $0.0 \%$ \\
\hline Q9 & $\begin{array}{l}\text { Overall management } \\
\text { of class }\end{array}$ & $46.7 \%$ & $40.0 \%$ & $10.0 \%$ & $3.3 \%$ & $0.0 \%$ \\
\hline Q10 & $\begin{array}{l}\text { Delivery of theory } \\
\text { materials }\end{array}$ & $43.8 \%$ & $37.5 \%$ & $12.5 \%$ & $6.3 \%$ & $0.0 \%$ \\
\hline Q11 & $\begin{array}{l}\text { Delivery of practical } \\
\text { materials }\end{array}$ & $54.8 \%$ & $32.3 \%$ & $12.9 \%$ & $0.0 \%$ & $0.0 \%$ \\
\hline
\end{tabular}




\section{Macrothink}

Table 2. Student previous videoconferencing experience and overall satisfaction with Zoom

\begin{tabular}{|c|c|c|c|}
\hline $\begin{array}{l}\text { Questi } \\
\text { on }\end{array}$ & & Yes & No \\
\hline Q1 & $\begin{array}{l}\text { Have you ever used video conferencing software to } \\
\text { study before? }\end{array}$ & $18.8 \%$ & $81.2 \%$ \\
\hline Q2 & Have you ever used Zoom prior to this semester? & $53.1 \%$ & $46.9 \%$ \\
\hline Q3 & $\begin{array}{l}\text { Do you usually like to use technology during } \\
\text { studying? }\end{array}$ & $87.5 \%$ & $12.5 \%$ \\
\hline Q4 & $\begin{array}{l}\text { Would you like to use Zoom in other courses you } \\
\text { might take in the future? }\end{array}$ & $75.0 \%$ & $25.0 \%$ \\
\hline Q5 & $\begin{array}{l}\text { Would you recommend using Zoom to any of your } \\
\text { friends? }\end{array}$ & $90.6 \%$ & $9.4 \%$ \\
\hline
\end{tabular}

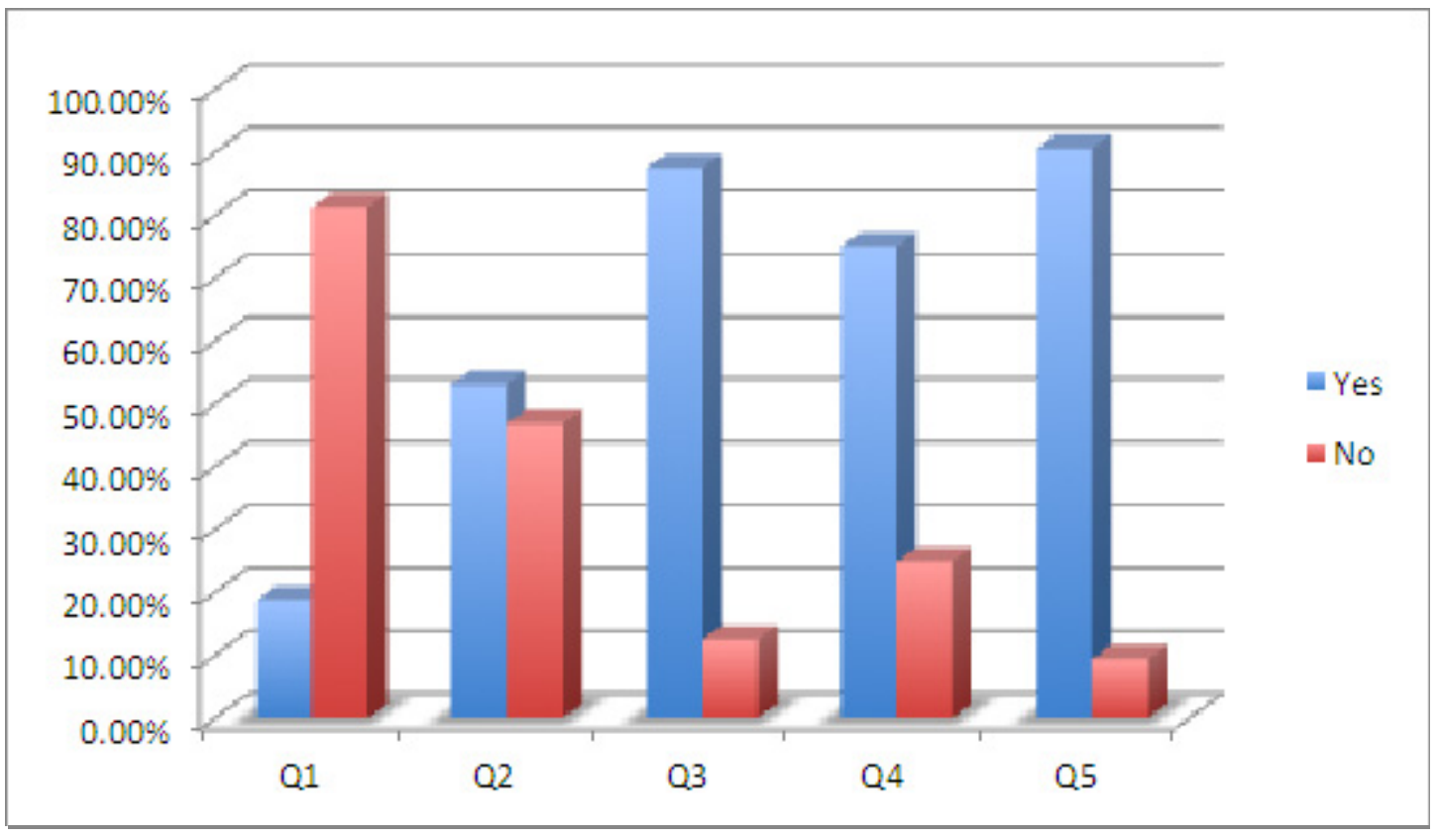

Figure 2. Results of student previous experience with video conferencing.

\section{Guidelines For Using Zoom When Teaching}

To use Zoom effectively as a course delivery tool, the faculty member should consider the following technical and pedagogical guidelines. These guidelines are based on lessons 
learned through the first semester of teaching via Zoom.

- During the first week of teaching with Zoom, the faculty member must ensure that a technician is available to help students download the software and troubleshoot any technical issues. In particular, students may have issues with laptop audio drivers.

- Since Zoom operates in HD mode (1080p60), minimum bandwidth for instructor and student connections is $2560 \mathrm{kbps}$. Preferably, the instructor should have a wired connection with a dedicated IP address and guaranteed bandwidth on the network.

- Students and instructor are advised to have a good quality microphone/headset, preferably with a noise reduction feature.

- All users should upgrade from the free Zoom account to the Educational / Business Plan so that classes can run for more than 40 minutes.

- The instructor should create a recurring meeting time for classes within the institution's online calendar system. Students should be sent a meeting invitation, with the class URL included. This class URL should also be added to the class page on the institution's Learning Management System (LMS).

- In the first class, the instructor should ask students to introduce themselves while the camera is directed at them. The introduction should include a brief description of what each student expects from the class.

- Additionally, the instructor should introduce the students to the features of Zoom in the first class and discuss the reasons for and benefits of using it. In particular, students should be informed how Zoom can improve their learning.

- For all classes, students should log in to Zoom using their names and ID numbers.

- The instructor should give the students the option to record the session at the beginning of each class.

- When using screen sharing mode, the instructor cannot easily see all the students. Therefore, it is recommended to pause every five minutes or so and ask students suitable questions to ensure they are tracking with the class.

While it is possible to have multiple students in one room with the Zoom feed projected on a screen, this tends to degrade both the audio quality and the interactive experience. It is better to have each student attend the course directly from his/her laptop or tablet. If more than one student is sitting in the same room, then the following points apply:

- Students should use headsets to avoid echoes.

- One student should be nominated to have his/her microphone on at all times, so that audio in the classroom can be monitored. All other students should mute their microphones until they have a question.

The following additional suggestions may improve students' interaction and interest in the session: 
- Use appropriate animation tools when screen sharing.

- Give students equal opportunities to participate in the lesson by asking questions of those who have not participated.

- During practical sessions, have the students pose their questions to all participants using the chatting console and encourage their classmates to help in the troubleshooting process.

- The instructor should answer every question and ensure that all students understand that they can interrupt the lecture at any time to ask questions and have them answered.

- Give the students time in the class to complete some of their work and to present it to the rest of the class. This work may include a problem that needs solving, a concept that needs explanation, and so on.

- If the instructor needs to provide additional explanation or troubleshoot a technical problem, the students should to share their desktops and give mouse control to the instructor.

- During class, the instructor should browse through the students' live videos and interact with those who seem distracted by external issues. The instructor should also use give students online quizzes via the LMS, and then provide feedback online.

- Students can use the private chat feature to ask questions and interact with the instructor without disturbing the other students.

- Instructors should reserve one or two office hours each week for students to discuss issues, ask for clarifications or receive feedback through Zoom.

- The instructor should create small working group within the class that comprise students of different academic levels. Each group should have dedicated time with the instructor during the week.

- Students should be informed that all institutional rules and regulations governing classrooms must be respected while they are attending Zoom classes.

- Attendance should be taken based on the list of participants in the participants' window.

\section{Zoom Utilisation at HCT}

Although the CISAC Faculty has been using Zoom since August 2013, November 2013 was the first month that the Faculty started to benefit from the educational licence. Zoom utilisation during November 2013 can be summarised as follows:

Total video meeting time: There was a total of 73,122 Zoom meeting minutes during November 2013, which equates to 1,218 hours or an average of 43 hours per day, including weekends. 
Participants: 2,411 people participated in Zoom meetings during November 2013, i.e. an average of 86 people per day.

Number of meetings: The total number of meetings during November 2013 was 315, which breaks down to 11 meetings per day on average, including weekends.

Table 3. below summarises the comparison between cloud video conferencing technology and traditional video conferencing rooms

\begin{tabular}{|c|c|c|}
\hline Property & $\begin{array}{l}\text { Traditional Video } \\
\text { Conferencing }\end{array}$ & Cloud Video Conferencing \\
\hline Access & $\begin{array}{l}\text { Access to the video conference } \\
\text { room is limited regarding the } \\
\text { location of the room, time, } \\
\text { number of people that the room } \\
\text { can accommodate and number } \\
\text { of links. }\end{array}$ & $\begin{array}{l}\text { Users can join the video conference directly } \\
\text { from PCs and mobile devices and can host } \\
\text { an unlimited number of meetings for an } \\
\text { unlimited time. If a room is busy, the user } \\
\text { can start a new meeting and invite users to } \\
\text { attend. Up to } 25 \text { devices can join any } \\
\text { meeting; each device can accommodate } \\
\text { multiple users sitting in the same room. }\end{array}$ \\
\hline Cost & $\begin{array}{l}\text { The current cost to establish a } \\
\text { system of video conferencing } \\
\text { facilities is approximately } 5 \mathrm{M} \\
\text { AED for four video } \\
\text { conferencing rooms }\end{array}$ & $\begin{array}{l}\text { A Zoom educational account for } 500 \text { hosts } \\
\text { who can host unlimited meetings costs AED } \\
5,000 \text {. }\end{array}$ \\
\hline Utilization & $\begin{array}{l}\text { To achieve similar utilisation } \\
\text { would required at least } 50 \\
\text { traditional video conference } \\
\text { rooms. }\end{array}$ & $\begin{array}{l}\text { Zoom is still preferable as it allows } \\
\text { participants to connect from their offices. }\end{array}$ \\
\hline $\begin{array}{l}\text { System } \\
\text { Integration }\end{array}$ & $\begin{array}{l}\text { Traditional video conferencing } \\
\text { software is typically a } \\
\text { standalone technology that is } \\
\text { installed within the } \\
\text { organization premises and is } \\
\text { very difficult to integrate it with } \\
\text { other emerging technologies }\end{array}$ & $\begin{array}{l}\text { Zoom can be integrated easily with other } \\
\text { emerging cloud computing solutions and } \\
\text { services such as Dropbox and BOX through } \\
\text { a technology called REST Application } \\
\text { Programing Interface (API). This is an } \\
\text { advanced feature for developers who are } \\
\text { looking to have Zoom inside other } \\
\text { Cloud-based systems and customize their } \\
\text { infrastructure cloud environment. }\end{array}$ \\
\hline
\end{tabular}




\section{Future Research}

A number of directions for future research present themselves. First, a great number of students should be surveyed to validate the findings of this paper. Results should be cross-referenced against demographic factors such as gender, level of studies, type of course $\&$ geographic location.

Second, the current group of students should be studied again, during a second Zoom course, to determine the benefits of prolonged exposure to this type of class.

Third, faculty members who are teaching through Zoom should be interviewed in-depth to determine the advantages and disadvantages of the technology from their view.

\section{Conclusion}

Cloud video conferencing technologies such as Zoom, which offer HD video quality, screen sharing and recording capability, can bring new benefits to education. In addition to connecting staff and management teams in remote locations to form one effective team, it allows students and faculty members to enjoy 'anytime, anywhere' collaboration opportunities. Faculty members can use this technology to discuss course progress, share teaching practices and course content, and to collaborate on applied research. The technology also enhances opportunities for staff professional development by eliminating logistical issues such as room booking, travel and waste of time $\&$ resources.

Similar to any technology, faculty and students alike need to consider some technical issues and may need to experience a pedagogical shift. However, this is a great opportunity for faculty members to provide students with new opportunities to interact through group discussions, screen sharing, group projects, demonstrations and presentations. In summary, cloud video conferencing can make the educational experience a much more effective and enjoyable one for all.

\section{References}

Aydin, I. E. (2012). Relationship between Affective Learning, Instructor Attractiveness and Instructor Evaluation in Videoconference-Based Distance Education Courses. Turkish Online Journal of Educational Technology, 11(4), 247-252.

Breny Bontempi, J. M., Runyan, C. W., \& Heath, J. (1999). Training by satellite: Planning and evaluating a video conference for injury prevention practitioners. Journal of Community Health, 6(24), 451-466. http://dx.doi.org/10.1023/A:1018746706693

Lim, J., \& Freed, S. (2009). We Have the Videoconference Equipment Installed, Now What? Qualitative Report, 14(3), 433-453.

Brown, K. D. (2011). Teaching what really happened: How to avoid the tyranny of textbooks and get students excited about doing history. The Journal of Negro Education, 80(2), 177-179.

Journell, W., \& Dressman, M. (2011). Using Videoconferences to Diversify Classrooms 


\section{Macrothink}

Electronically. Clearing House: A Journal of Educational Strategies. Issues and Ideas, 84(3), 109-113.

Merryfield, M. M. (2000). Why aren't teachers being prepared to teach for diversity, equity, and global interconnectedness? A study of lived experiences in the making of multicultural and global educators. Teaching and Teacher Education, 16(4), 429-23. http://dx.doi.org/10.1016/S0742-051X(00)00004-4

Parrish, M. (2008). Dancing the Distance: iDance Arizona Videoconferencing Reaches Rural Communities. Research in Dance Education, 9(2), 187-208. http://dx.doi.org/10.1080/14647890802087811

\section{Copyright Disclaimer}

Copyright reserved by the author(s).

This article is an open-access article distributed under the terms and conditions of the Creative Commons Attribution license (http://creativecommons.org/licenses/by/3.0/). 